УДК 378

\title{
ЗНАЧЕНИЕ НАСЛЕДИЯ ИСТОРИЧЕСКИХ ЛИЧНОСТЕЙ В ОБУЧЕНИИ СТУДЕНТОВ НАПРАВЛЕНИЯ ПОДГОТОВКИ «ДИЗАЙН»
}

\begin{abstract}
Васильева Дарья Алексеевна студент

Научный руководитель: Салтыкова Галина Михайловна к.П.н., доцент ФГБОУ ВО Московский педагогический государственный университет
\end{abstract}

Аннотация: В статье рассматриваются вопросы обучения студентов направления подготовки «Дизайн», приобретения разносторонних знаний, «универсальных» навыков и компетенций. Рассматривается принцип «универсальности» и всестороннего образования в историческом контексте наследия Леонардо да Винчи и Альбрехта Дюрера. Поднимаются вопросы дизайн-деятельности $\mathrm{y}$ студентов направления «Дизайн», а также необходимости обширных знаний и профессиональных компетенций в разных сферах деятельности.

Ключевые слова: дизайн, педагогика, компетентность, дизайнобразование, научно-исследовательская деятельность, Альбрехт Дюрер, Леонардо да Винчи, художественное образование, профессиональное становление дизайнера.

\section{THE VALUE OF HERITAGE OF HISTORICAL PERSONALITIES IN TRAINING STUDENTS' DIRECTION "DESIGN"}

\section{Vasilyeva Darya Alekseevna Scientific adviser: Saltykova Galina Mikhailovna}

\begin{abstract}
The article discusses the issues of teaching students in the direction of training "Design", the acquisition of versatile knowledge, "universal" skills and competencies. The principle of "universality" and comprehensive education in the historical context of the legacy of Leonardo da Vinci and Albrecht Durer is
\end{abstract}


considered. Questions of design activity at students of the direction "design" and the need for extensive knowledge and professional competence in various fields.

Key words: design, pedagogy, competence, design education, research activities, Albrecht Durer, Leonardo da Vinci, art education, professional development of a designer.

В современном мире большинство объектов производства так или иначе связаны с дизайн-деятельностью. Издание, которое мы читаем, транспорт, которым мы пользуемся, предметы быта, мебель, посуда, средовое окружение дома, в офисе, или в парке. Все эти объекты в той или иной степени не обходятся без вклада дизайнера. Дизайн-деятельность охватывает широкий спектр знаний и технологий, которые необходимы для проектирования качественного, функционального и эстетичного объекта. Для будущей профессиональной деятельности студентам необходимы разносторонние знания, разноплановые навыки и компетенции. Ведь дизайнер является своего рода проводником, посредником между воплощением разнообразных объектов, находящихся в среде жизнедеятельности человека, технологиями и пользователем [1, с. 225].

Д.А. Норманном дизайн-деятельность определялся как творческая, проектная деятельность с целью определения формальных качеств промышленных изделий. Такого рода качества представляют совокупность структуры, функции, эстетики внешнего вида проектируемого объекта, которая позже представит продукт цельным законченным, как для производителя, так и для потребителя [2, с. 49]. Поэтому важно, чтобы будущий или состоявшийся дизайнер, постоянно повышал уровень своей квалификации и спектр своих знаний.

Для любого дизайнера непререкаемыми авторитетами в профессиональной деятельности являются исторические личности, мастера внесшие глобальный вклад в проектную деятельность, оставившие колоссальное культурное наследие. Такими «универсальными» мастерами в первую очередь являются Леонардо да Винчи и Альбрехта Дюрера. Их исследования, труды, проекты можно считать абсолютно дизайнерскими. Практически каждый проект мастеров основан на предпроектном исследовании, имеет функциональную практикоориентированную направленность, эстетическое воплощение. Объем знаний, широта интересов, владение профессиональными навыками поражает своим разнообразием. Да 
Винчи, будучи великолепным художником, постоянно изучал нечто новое, неизведанное. В анатомических зарисовках художника детально зафиксированы его исследования человеческого тела. Его исследования строения и пропорций скелета, крепления и функционирования мышц и, работы различных органов, легли в основу современной биомеханики. Основываясь на изучении анатомии и функциональности человеческого тела (то, что позднее сложилось как антропометрия и эргономика), им было разработано немалое количество устройств, а их детальность и проработка послужила прообразом современного технического и проектного рисунка [3, c.22]. Витрувианский человек да Винчи, пожалуй, первый визуальнографический пример, документирующий совокупность науки и искусства. Позднее изучение пропорций будут в исследованиях у Альбрехта Дюрера и Ле Корбюзье (рис.1-2).
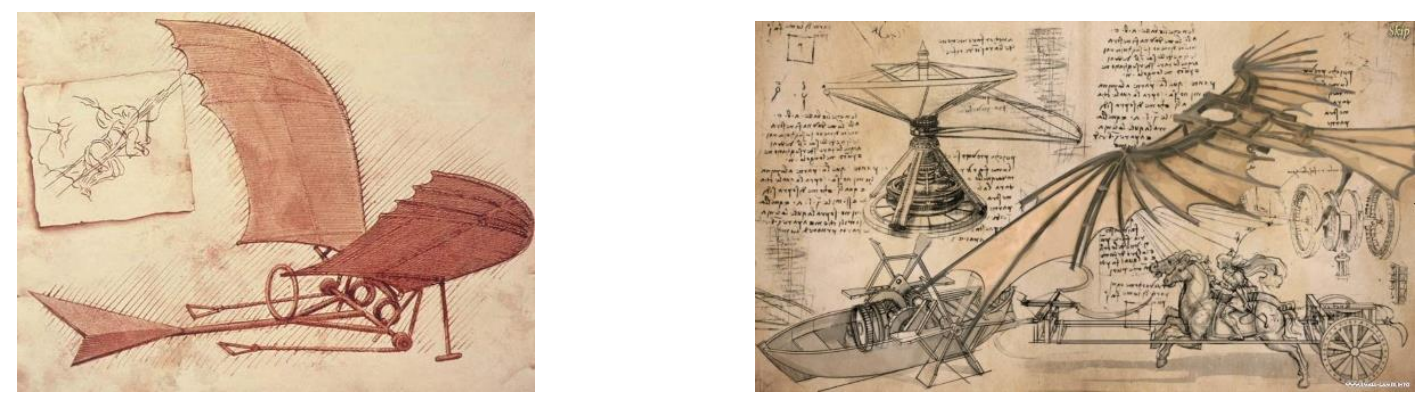

Рис. 1. Исследования Леонардо да Винчи
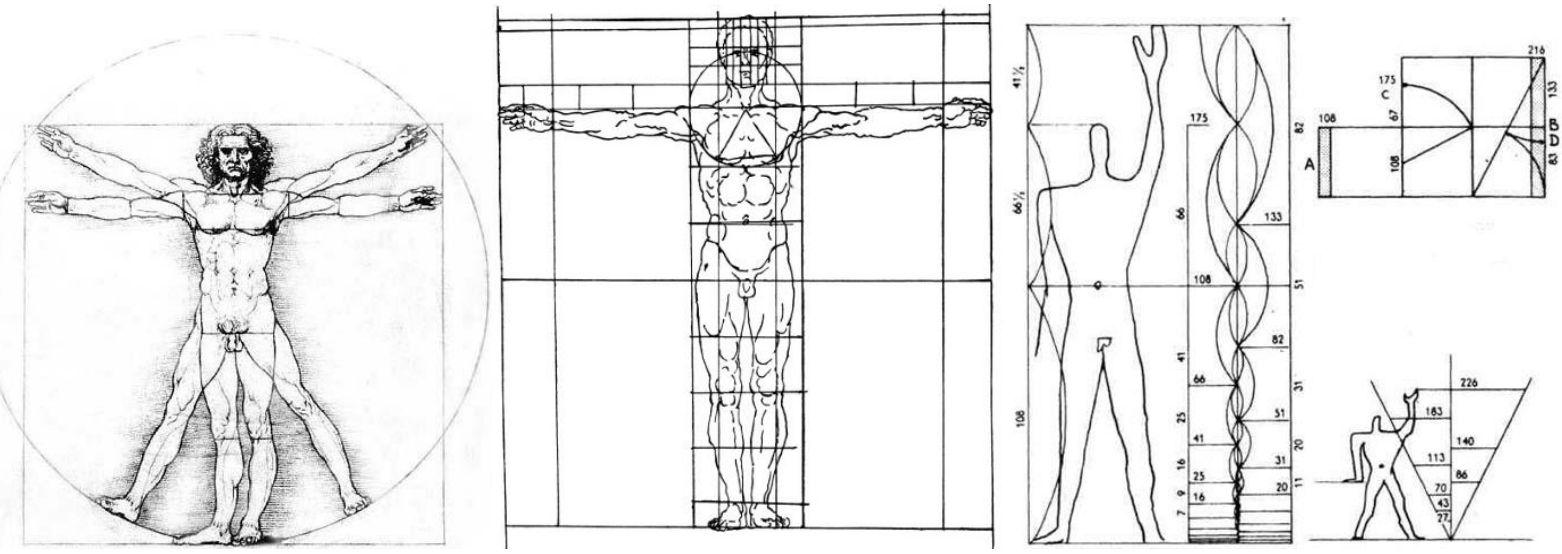

Рис. 2. Исследование антропометрических пропорций

\section{(Леонардо да Винчи «Витрувианский человек», Альбрехт Дюрер «4 книги о пропорциях», Ле Корбюзье «Модулор»)}

Как и Леонардо да Винчи, Альбрехт Дюрер оставил колоссальное наследие своих трудов и работ. Он являл собой новый на тот момент тип художника-ученого, «Титан по силе мысли, страсти и характеру, по 208 
многосторонности и учености» [4, с. 7]. Он вел разработки в типографике, архитектуре, математике, графике, живописи и многом другом. Дюрер еще в 15 веке предложил строить сложные объекты как геометрические формы, последовательно описывая процесс в своих «Руководствах». Позднее такая методика легла в основу системы обучения будущих художников, графиков, дизайнеров и архитекторов.-Например, метод построения головы по принципу «обрубовки» на курсах «Академического рисунка» [5, с. 188]. В руководствах Дюрера человеческое тело, сложное для воспроизведения на момент обучения, структурировано как совокупность геометрических форм (рис.2). Такой метод позволяет разбить сложную форму на простые, благодаря чему «разобраться» в анатомии на практике может как профессионал, так и ученик. Многие методы из его руководств в последствии легли в основу педагогической практики обучения студентов.
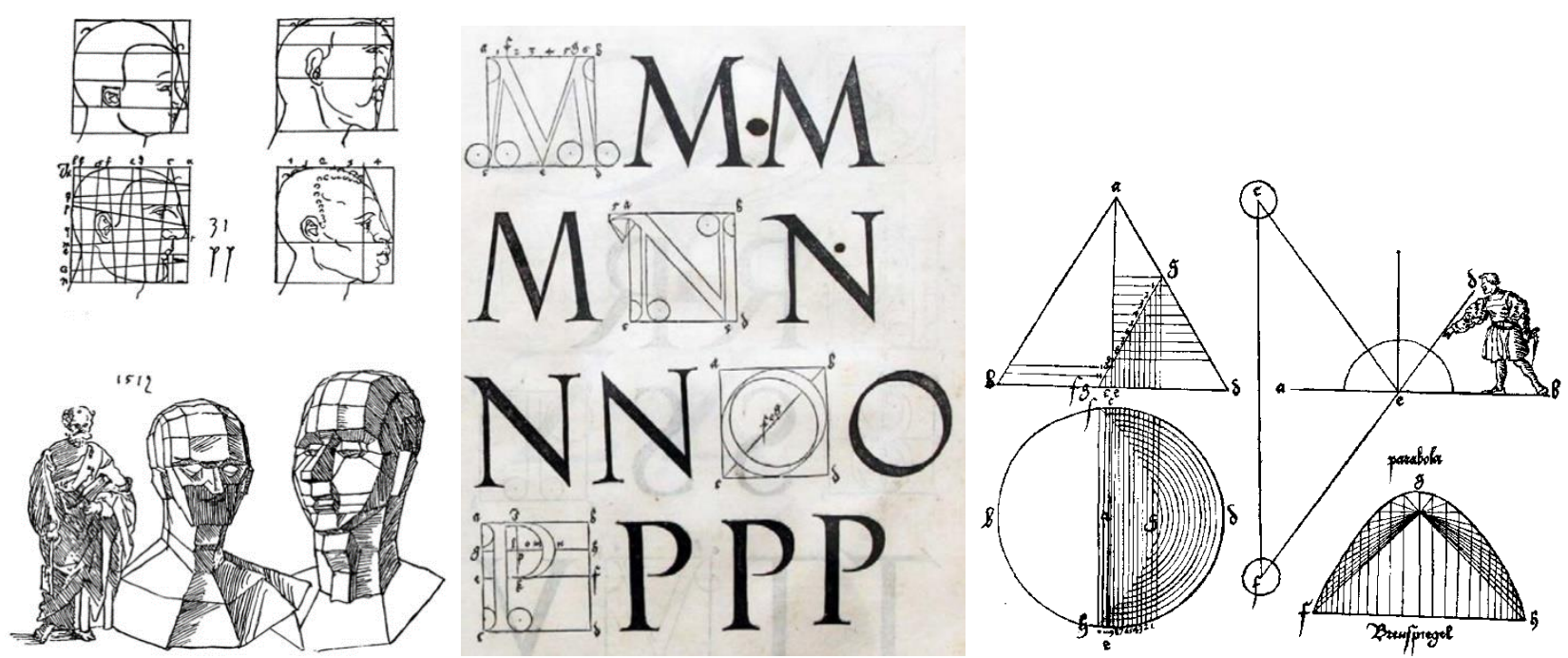

Рис. 3. Из исследований пропорций. Альбрехт Дюрер

Профессия дизайнера требует немалой мобильности и универсальности в освоении новых знаний, технологий, специальных видов деятельности. При чем как внутрипрофессиональных, так иногда в смежных областях профессиональной деятельности. Такая разноплановость требует от дизайнера постоянного развития, включая научно-исследовательскую деятельность. Мерой в дизайне является человек. А результат работы дизайнера предназначены для пользования человеком. Именно поэтому в обучении студентов направления подготовки «Дизайн» помимо практических и специальных дисциплин, необходимы дисциплины, включающие вопросы по естествознанию и экологии, физики и механики, истории и психологии. В 
рамках дизайн-исследований можно выделить пять основных научных областей, непосредственно связанных с дизайн-деятельностью:

1. Теория науки.

2. Теория мышления.

3. Методология системно-структурного анализа.

4. Теория деятельности.

5. Семиотика $[6$, с.68].

О разноплановости дизайн-деятельности О.В. Чернышев сформулировал определение следующим образом: «...дизайн-деятельность - это синтез принципов научного, технического и художественного творчества в комплексном решении социально-значимых проблем и реализации тенденций развития материального мира» [7, с.130].

Профессионализм дизайнера зависит и от его личностных качеств, например, амбициозность, целеустремленность, способность к самообразованию и самосовершенствованию и т.д. Эти качества способствуют профессионально актуализироваться к быстро меняющейся жизни общества, ее новым условиям, быстро развивающимся технологиям. Дизайнеры заняты как выполнением творческой, проектной задачи, так и производственнотехнологической. Нередко в дизайн-проект входит разработка макета промышленного изделия, подготовка технической документации и последующий запуск в производство, контроль этого производства вплоть до итога и реализации. Студенческие проекты обязательно включают освоение производственного цикла. Например, разрабатывая упаковку, студент обязан знать особенности производственных циклов, свойства и специфику материалов, их совместимость, особенности транспортировки, хранения и эксплуатации, как обеспечить безопасность и эргономичность. Обязательный этап - испытание модели на практике. Поэтому в обучении будущих дизайнеров важно изучение смежные видов деятельности. В ходе изучения профессиональных дисциплин студент дизайнер должен научится решать поставленные задачи на практике. Практико-ориентированная деятельность позволит получить необходимый опыт и навыки.

Формирование разносторонних и межпредметных навыков в образовании студента направления подготовки «Дизайн», ориентированных на практическую деятельность, крайне необходимо для будущего квалифицированного профессионала. Знания, навыки и способности, приобретенные в процессе обучения - база для будущей профессиональной 
деятельности. Дизайнеру необходимо познавать новое и развиваться в различных направлениях и сферах деятельности.

\section{Список литературы}

1. Салтыкова Г.М. Технологии в дизайн-образовании в высшей школе. // Преподаватель XXI век. - 2018, № 2 часть 1. С. 223-230 (1,2 п.л.) ВАК

2. Хайруллина Э.Р. Формирование готовности студента-дизайнера к производственно-технологической деятельности / Эльмира. Робертовна. Хайруллина, Ларианна. Юрьевна. Королева // Международный научноисследовательский журнал. — 2012. — №6 (6). — С. 48-50.

3. Леонардо да Винчи // 100 человек, которые изменили ход истории : журнал / Под ред. А. Жарковой. - M.: De Agortini, 2008. - Вып. 1. - С. 131. - ISSN 1996-8469

4. Альбрехт Дюрер. Дневники. Письма. Трактаты // Авторский сборник - М: Искусство, 1957, 484 с.

5. Лыкова Елена Сергеевна История становления предмета «Изобразительное искусство» // ОНВ. 2014. №3 (129). - С. 187-190.

6. Генисаретский О.И. Теоретические и методологические исследования в дизайне. Избранные материалы / О.И. Генисаретский, Е.М. Бизунова. - М: Шк. культ. политики, 2004 - 142 с.

7. Чернышев О.В. Дизайн-образование: новая модель профессиональной подготовки дизайнеров. / О.В. Чернышев. - Минск: Пропилеи, 2006. - 280 с.

(C) Д.А. Васильева, 2021 